\title{
Focus on Basal Cell Carcinoma
}

\author{
Venura Samarasinghe, ${ }^{1,2}$ Vishal Madan, ${ }^{1,2}$ and John T. Lear ${ }^{1,2}$ \\ ${ }^{1}$ Manchester Royal Infirmary, Central Manchester and Manchester Childrens' Hospital NHS Trust, \\ Oxford Road, Manchester M13 9WL, UK \\ ${ }^{2}$ The Dermatology Centre, Salford Royal Hospital NHS Foundation Trust, Stott Lane, Salford M6 8HD, UK
}

Correspondence should be addressed to Venura Samarasinghe, venuras1@hotmail.com

Received 1 July 2010; Accepted 10 August 2010

Academic Editor: Arash Kimyai-Asadi

Copyright ( 2011 Venura Samarasinghe et al. This is an open access article distributed under the Creative Commons Attribution License, which permits unrestricted use, distribution, and reproduction in any medium, provided the original work is properly cited.

\begin{abstract}
Nonmelanoma skin cancers (NMSCs), which include basal and squamous cell cancers are the most common human cancers. BCCs have a relatively low metastatic rate and slow growth and are frequently underreported. Whilst there is a definite role of sunexposure in the pathogenesis of BCC, several additional complex genotypic, phenotypic and environmental factors are contributory. The high prevalence and the frequent occurrence of multiple primary BCC in affected individuals make them an important public health problem. This has led to a substantial increase in search for newer noninvasive treatments for BCC. Surgical excision with predetermined margins remains the mainstay treatment for most BCC. Of the newer non-invasive treatments only photodynamic therapy and topical imiquimod have become established in the treatment of certain BCC subtypes, while the search for other more effective and tissue salvaging therapies continues. This paper focuses on the pathogenesis and management of BCC.
\end{abstract}

\section{Introduction}

Basal cell carcinoma (BCC) is the commonest skin cancer in Caucasians and its incidence continues to increase worldwide [1]. First described in 1824 by Jacob, it is a slow growing, locally destructive, skin tumour of the epidermis [2]. Average life time risk of developing a BCC is approximately $30 \%$ in Caucasians, and represents a significant public health issue [3]. Australia has the highest incidence of BCC in world with 1383 new cases diagnosed for every 100,000 population in 2008 [4]. In UK there are estimated 53,000 new cases per year, and 153.9 cases per 100, 000 person years [5]. Figures for incidence are likely to be significantly underestimated in the UK as BCCs are not routinely registered.

Fortunately in respect of the high incidence, BCCs rarely metastasise. Metastatic rate is $<0.1 \%$, and reported sites of metastasis are skeletal and pulmonary [6, 7]. Risk factors for metastasis are neglect over many years, perineural invasion, size over $10 \mathrm{~cm}^{2}$, and basisquamous and morphoeic subtypes [8]. Tumours left untreated can cause extensive tissue destruction, disfigurement, infiltrate cartilage, muscle or bone with even intracranial extension. BCCs may also develop in scars or sebaceous naevi and are associated with several genetic syndromes including basal cell naevus (Gorlin's) syndrome, xeroderma pigmentosa, Bazex syndrome, and albinism [9].

There are several subtypes of BCC: nodular, cystic, superficial, morphoeic (sclerosing), keratotic, pigmented, and micronodular [10]. Nodular BCCs are the most common in UK, though $10-40 \%$ show a mixed pattern of 2 or more subtypes [11]. Most nodular and morphoeic subtypes are found on the head and neck, contrasting with $46 \%$ of superficial BCC occurring over truncal sites [12].

Once a BCC is diagnosed, risk of further BCC is approximately 10-fold over the general population. Risk factors for developing further BCCs are multiple BCC at presentation, older age at presentation, and index BCC over $1 \mathrm{~cm}$. BCC arising on the trunk are usually associated with development of further truncal BCC [10]. Overall risk of further BCC is approximately $46 \%$ over a 10 -year period [13].

\section{Aetiology}

Aetiology of BCC is a multifactorial combination of genotype, phenotype, and environmental factors. Ultraviolet 
radiation is one the most significant factors, demonstrated by the global highest incidence in areas closer to the equator, whilst Finland has the lowest incidence of all European countries. UVB irradiation directly damages cellular DNA and RNA causing covalent bonding between adjacent pyrimidines, and formation of mutagenic products. UVA produces the formation of toxic reactive oxygen species [14]. Overall intermittent sun exposure and childhood sun exposure may be of more importance than cumulative sun exposure [15, 16].

Several genes have been associated with BCC development. Cytochrome 450 (CYP) and glutathione S-transferase (GST) are both involved in detoxifying various mutagens. Specific polymorphisms within these supergenes have been identified, in particular GSTM1, GSTT1, GSTP1 and CYP2D6 [17, 18]. CYP2D6 may be associated with the development of multiple BCCs also [19]. Basal cell naevus syndrome (BCNS) is due to mutation in the PTCH gene located on chromosome 9q22. PTCH gene is the human homologue of the drosophilia patched gene, negatively regulating Hedgehog signalling via inhibition of Smoothened (Smo), a transmembrane protein. Inactivating mutations of PTCH in BCNS stimulate aberrant Hedgehog signalling and subsequent BCC development. Sporadic BCCs have also been shown to contain PTCH mutations in up to $68 \%$ of cases. Mutations in tumour suppressor gene p53 cause inactivation of the gene and development of tumours resistant to apoptosis. Up to $53 \%$ of BCCs may have a single allele mutation of p53 [20]. Skin type is associated with melanocortin 1 receptor (MC1R) polymorphisms and an independent risk factor for BCC. Eye colour and tanning function is associated with polymorphisms in tyrosinase and subsequent risk of BCC development [21].

Other important risk factors are age over 40, sun bed use, phototherapy, radiotherapy, male sex, and arsenic exposure [10]. Immunosuppression confers a 10-100 increased risk over the general population, a risk which increases with longer duration of immunosuppression. Fair skin types (Fitzpatrick skin type I and II) are also at increased risk of developing BCC, with 19 times reduced risk in darker skin [14].

\section{Diagnosis}

Diagnosis is usually clinical. Clinical features are dependent on the subtype of BCC. Nodular or cystic BCCs present as raised red, pearly, translucent lesions with peripheral telangiectasia (Figure 1). Superficial BCC may mimic discoid eczema or Bowen's disease whilst morphoeic BCC presents as a subtle scar-like plaque (Figures 2 and 3). Dermatoscopy may be helpful to identify arborising blood vessels, ulceration, maple-leaf-like areas characteristic of BCC [22]. Computer tomography or magnetic resonance imaging is performed for bony, vascular, or major nerve invasion. Skin biopsy is performed in the majority of cases to aid diagnosis and identify subtype of BCC for treatment planning.

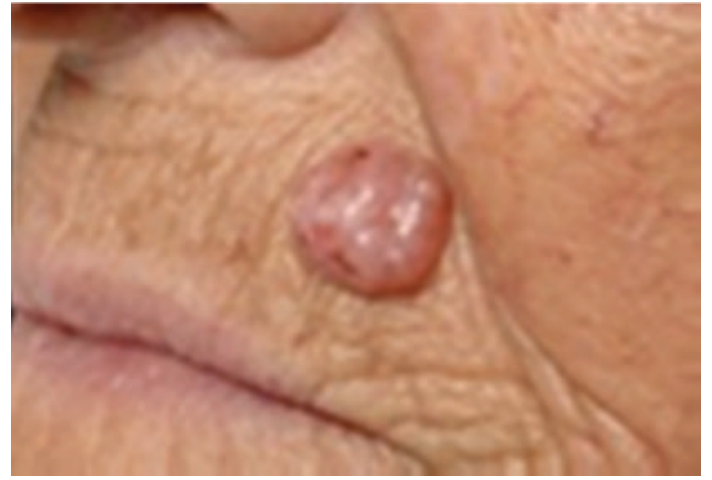

Figure 1: Nodulo-cystic BCC.

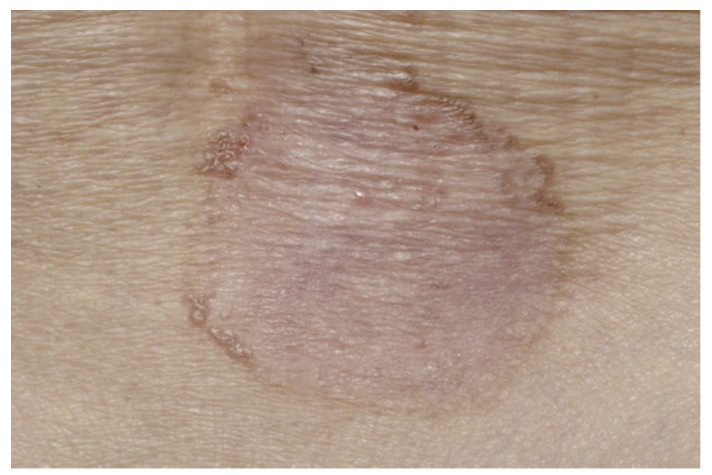

FIgURE 2: Superficial BCC.

TABLE 1: Factors associated with high risk of future BCC recurrence.

High Risk BCC

Aggressive histological subtype; morphoeic, micronodular

Large size $>2 \mathrm{~cm}$

Perineural, perivascular invasion

Central facial site; periocular, nasal, perioral

Recurrent BCC

\section{Treatment}

Treatment of BCC is hampered by poor quality, conflicting research with often short-term 1 year clearance data. Most studies are open, uncontrolled, and retrospective in nature. The key decision for treatment is identifying high versus low risk BCC (Table 1). Standard surgical excision and Moh's micrographic surgery allows histological confirmation of tumour clearance and generally remains gold standard for high risk $\mathrm{BCC}$, whilst the other treatment modalities rely on clinical observation at followup to confirm treatment success, with higher recurrence rate at 5-year review.

\section{Surgical Excision}

The BCC is excised with a predetermined margin of usually 3-4 mm of normal skin to ensure the lesion is fully excised. The excised tissue is placed in formalin, embedded, and cut 


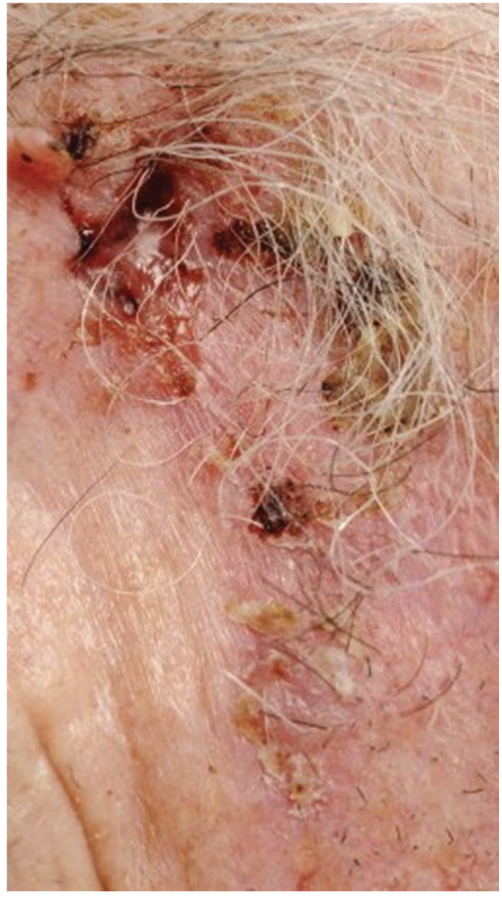

FIgure 3: Morphoeic BCC.

into interrupted vertical sections akin to a "breadloaf" for histological review. As the entire margin is not examined, this allows for sampling error and reporting of BCC to be completely excised when in fact they may not be. In 2004 a prospective randomised controlled study of surgical excision versus Mohs' micrographic surgery by Smeets et al., found of 199 primary facial BCC excised with $3 \mathrm{~mm}$ margins, 18\% were incompletely excised at first attempt, requiring further excision [23]. Tumours which were of aggressive histological subtype were significantly more likely to be incompletely excised initially. $14 \%$ had complications, most commonly wound infection, or necrosis of graft or flap rather than bleeding or haematoma. Overall recurrence rate of BCC with surgical excision was $4.1 \%$ at 5 year followup. A larger retrospective review by Rowe et al., of all studies published since 1947 found a higher recurrence rate of 10.1\% at 5-year followup for standard surgical excision [24].

\section{Moh's Micrographic Surgery}

Moh's micrographic surgery (MMS) was first reported in 1941 by Mohs [25]. Excised tissue is frozen and sectioned horizontally. The entire margin is intraoperatively histologically examined and further staged excision is performed only where the tumour is located microscopically. This allows for greater histological accuracy of complete tumour resection and increased tissue conservation. In the study by Smeets et al., comparing surgical excision versus Moh's micrographic surgery, 198 patients were randomised to the MMS arm. Complication rate for MMS was $12 \%$, most commonly wound infection and flap/ graft necrosis. 5-year recurrence rate was $2.1 \%$, which was not significantly different in comparison to surgical excision $(P=.23)$. Neither was a significant difference found in patient perception of cosmetic appearance between MMS and surgical excision for primary BCC.

However for recurrent facial BCC, MMS is the treatment of choice. 204 patients with recurrent facial BCC were also randomised to MMS versus surgical excision. At 5-years $2.4 \%$ recurred in the MMS group in comparison to $12.1 \%$ in the surgical group, confirming significantly lower recurrence in the MMS group $(P=.015)$. In addition $30 \%$ of tumours in surgical group were initially incompletely excised and required further surgery [23]. Similar results were found in Rowe et al.'s retrospective review of all studies since 1945, with 1.0\% 5-year recurrence for untreated BCC with MMS and $5.6 \% 5$ year recurrence rates for treatment of recurrent BCC with MMS [24, 26].

\section{Radiotherapy}

Radiotherapy (RT) can be effective for primary BCC, recurrent BCC or as adjuvant for incompletely excised BCC in patients where further surgery is neither possible nor appropriate. Radiotherapy is a mixture of superficial, electron beam, and brachytherapy for curved surfaces. Treatment in fractions over several visits may produce better cosmetic outcomes than a single fraction treatment [10]. Radiotherapy is contraindicated in radiotherapy recurrent BCC, genetic syndromes predisposing to skin cancer and connective tissue disease. Significant side effects are radionecrosis, atrophy, and telangiectasia. Skin cancers can arise from radiotherapy field scars and should be avoided in younger age groups.

A randomised trial of 347 patients compared radiotherapy versus surgical excision with frozen sections for facial BCC less than $4 \mathrm{~cm}$ found significantly more recurrence occurred in the radiotherapy group $(7.3 \%)$ than the surgical group $(0.7 \%)$ at 4 -year followup (RR $0.09,95 \% \mathrm{CI}, 0.01$ to $0.69)$. Cosmetic outcome also significantly favoured surgical excision at 4 years with $87 \%$ of patients assessing the surgical scar as good, compared to $69 \%$ after radiotherapy $(P<.01)$ $[27,28]$.

\section{Curettage and Cautery}

Curettage and cautery is one of the commonest tools used by dermatologists in management of BCC. The tumour is scraped with a curette and then treated with electrocautery to control bleeding and destroy any cancer cells at the base and margin of the wound. The cycle is repeated either once or twice for increased efficacy. A study of 898 BCC reported a 5 year cumulative recurrence rate of 6-19\%. Recurrence was higher for central facial areas [29]. A further study of 2314 BCC treated with curettage and cautery also confirmed significantly higher recurrence for facial BCCs [30].

\section{Cryotherapy}

Cryotherapy is a destructive method of treating BCC using liquid nitrogen to cause low cell temperature and 
necrosis. Significant variation occurs in technique, length, and number of freeze thaw cycles used. Side-effects include pain, blistering, infection, and scarring. A nonrandomised study of 93 patients comparing cryotherapy to radiotherapy, treated BCC with 2 freeze thaw cycles of freezing for 1 minute, and thaw of 90 seconds. At 2-year followup, in the cryotherapy group 39\% of BCCs had recurred, compared to $4 \%$ in the radiotherapy group. No significant difference was found in the cosmetic outcome between cryotherapy and radiotherapy [31]. Another study compared cryotherapy to surgical excision for head and neck superficial and nodular BCC, less than $2 \mathrm{~cm}$. Cryotherapy was performed using 2 freeze thaw cycles of freezing for 20 seconds, and thaw of 60 seconds. No difference in recurrence rate was found at 1 year, but there was a significantly better cosmetic outcome with surgical excision compared to cryotherapy [32].

\section{Photodynamic Therapy}

Photodynamic therapy (PDT) is performed by topical application of the prodrug 5-aminolaevulinic acid (ALA) or methyl aminolaevulinic (MAL) to the BCC. The prodrug is converted intracellularly into protoporphyrin IX (PpIX) via the heme pathway. The BCC is then irradiated with a light source and in the presence of oxygen, a cytotoxic reaction occurs within the target cells where the PpIX has accumulated. The light source is usually either $410 \mathrm{~nm}$ blue light or $630 \mathrm{~nm}$ red light to match the absorption peak for PpIX. Red light may be preferred with the lipophilic MAL for deeper tissue penetration. Superficial BCC has been shown to achieve $87 \%$ clearance, and better cosmesis than with curettage or cryotherapy [33].

For nodular BCC a study comparing MAL PDT with surgical excision in 101 patients showed a MAL PDT cure rate of $76 \%$ compared to $96 \%$ for surgical excision. Cosmesis was better for PDT with $87 \%$ of patients rated as good cosmetic outcome in comparison to $54 \%$ for surgery [34].

\section{Imiquimod}

Imiquimod is an immune response modifier, binding to cell surface toll receptor 7 and/or 8. Binding activates proinflammatory cytokine production and subsequent cytotoxic $\mathrm{T}$ cell mediated cell death. Studies of topical administration for low risk BCC at least 5 days per week confirmed $81 \%$ histological clearance at week 6 or 12 [35-37]. A further study of topical imiquimod applied 5 days per week for a total of 6 week in 182 patients found $69 \%$ remained clinically clear at a 5 year followup period [38]. Side effects included application site erythema, crusting, erosion, and pain.

\section{Conclusion}

Research has improved our understanding of the pathogenesis of basal cell carcinoma, and with this has arrived several new generation nonsurgical treatments. However Moh's micrographic surgery remains gold standard for high risk BCC. Choice of treatment for basal cell carcinoma is complex and must take into account tumour type, location, cosmesis, recurrence, comorbidity and patient preference.

\section{References}

[1] F. J. Bath-Hextall, W. Perkins, J. Bong, and H. C. Williams, "Interventions for basal cell carcinoma of the skin," Cochrane Database of Systematic Reviews, no. 1, Article ID CD003412, 2007.

[2] A. Jacob, "Observations respecting an ulcer of peculiar character, which attacks the eyelids and other parts of the face," Dublin Hospital Representative, vol. 4, pp. 232-239, 1824.

[3] J. T. Lear and A. G. Smith, "Basal cell carcinoma," Postgraduate Medical Journal, vol. 73, no. 863, pp. 538-542, 1997.

[4] http://www.health.gov.au/internet/skincancer/publishing.nsf/ Content/fact-2.

[5] F. Bath-Hextall, J. Leonardi-Bee, C. Smith, A. Meal, and R. Hubbard, "Trends in incidence of skin basal cell carcinoma. Additional evidence from a UK primary care database study," International Journal of Cancer, vol. 121, no. 9, pp. 2105-2108, 2007.

[6] P. T. Ting, R. Kasper, and J. P. Arlette, "Metastatic basal cell carcinoma: report of two cases and literature review," Journal of Cutaneous Medicine and Surgery, vol. 9, no. 1, pp. 10-15, 2005.

[7] J. S. Lo, S. N. Snow, G. T. Reizner, F. E. Mohs, P. O. Larson, and G. J. Hruza, "Metastatic basal cell carcinoma: report of twelve cases with a review of the literature," Journal of the American Academy of Dermatology, vol. 24, no. 5, pp. 715-719, 1991.

[8] H. W. Walling, S. W. Fosko, P. A. Geraminejad, D. C. Whitaker, and C. J. Arpey, "Aggressive basal cell carcinoma: presentation, pathogenesis, and management," Cancer and Metastasis Reviews, vol. 23, no. 3-4, pp. 389-402, 2004.

[9] A. Hauschild, H. Breuninger, R. Kaufmann et al., "Short German guidelines: basal cell carcinoma," Journal of the German Society of Dermatology, vol. 6, no. 1, pp. S2-S4, 2008.

[10] N. R. Telfer, G. B. Colver, and C. A. Morton, "Guidelines for the management of basal cell carcinoma," British Journal of Dermatology, vol. 159, no. 1, pp. 35-48, 2008.

[11] V. Madan, J. T. Lear, and R.-M. Szeimies, "Non-melanoma skin cancer," Lancet, vol. 375, no. 9715, pp. 673-685, 2010.

[12] R. I. Ceilley and J. Q. Del Rosso, "Current modalities and new advances in the treatment of basal cell carcinoma," International Journal of Dermatology, vol. 45, no. 5, pp. 489498, 2006.

[13] N. M. Richmond-Sinclair, N. Pandeya, R. S. Ware et al., "Incidence of basal cell carcinoma multiplicity and detailed anatomic distribution: longitudinal study of an Australian population," Journal of Investigative Dermatology, vol. 129, no. 2, pp. 323-328, 2009.

[14] J. Roewert-Huber, B. Lange-Asschenfeldt, E. Stockfleth, and H. Kerl, "Epidemiology and aetiology of basal cell carcinoma," British Journal of Dermatology, vol. 157, no. 2, pp. 47-51, 2007.

[15] A. Kricker, B. K. Armstrong, D. R. English, and P. J. Heenan, "Does intermittent sun exposure cause basal cell carcinoma? A case-control study in Western Aeustralia," International Journal of Cancer, vol. 60, no. 4, pp. 489-494, 1995.

[16] S. Rosso, R. Zanetti, C. Martinez et al., "The multicentre south European study 'Helios' II: different sun exposure patterns in the aetiology of basal cell and squamous cell carcinomas of the skin," British Journal of Cancer, vol. 73, no. 11, pp. 1447-1454, 1996. 
[17] J. T. Lear, A. H. M. Heagerty, A. Smith et al., "Multiple cutaneous basal cell carcinomas: glutathione S-transferase (GSTM1, GSTT1) and cytochrome P450 (CYP2D6, CYP1A1) polymorphisms influence tumour numbers and accrual," Carcinogenesis, vol. 17, no. 9, pp. 1891-1896, 1996.

[18] J. T. Lear, A. G. Smith, R. C. Strange, and A. A. Fryer, "Detoxifying enzyme genotypes and susceptibility to cutaneous malignancy," British Journal of Dermatology, vol. 142, no. 1, pp. 8-15, 2000.

[19] S. Ramachandran, A. A. Fryer, A. G. Smith et al., "Basal cell carcinomas: association of allelic variants with a highrisk subgroup of patients with the multiple presentation phenotype," Pharmacogenetics, vol. 11, no. 3, pp. 247-254, 2001.

[20] V. Madan, P. Hoban, R. C. Strange, A. A. Fryer, and J. T. Lear, "Genetics and risk factors for basal cell carcinoma," British Journal of Dermatology, vol. 154, supplement 1, pp. 5-7, 2006.

[21] A. Kyrgidis, T. G. Tzellos, K. Vahtsevanos et al., "New concepts for basal cell carcinoma. Demographic, clinical, histological risk factors and biomarkers. A systematic review of evidence regarding risk for tumour development, susceptibility for secondary primary and recurrence," Journal of Surgical Research, vol. 159, no. 1, pp. 545-556, 2010.

[22] D. Altamura, S. W. Menzies, G. Argenziano et al., "Dermatoscopy of basal cell carcinoma: morphologic variability of global and local features and accuracy of diagnosis," Journal of the American Academy of Dermatology, vol. 62, pp. 67-75, 2010.

[23] N. W. J. Smeets, G. A. M. Krekels, J. U. Ostertag et al., "Surgical excision vs Mohs' micrographic surgery for basal-cell carcinoma of the face: randomised controlled trial," Lancet, vol. 364, no. 9447, pp. 1766-1772, 2004.

[24] D. E. Rowe, R. J. Carroll, and C. L. Day Jr., "Long-term recurrence rates in previously untreated (primary) basal cell carcinoma: implications for patient follow-up," Journal of Dermatologic Surgery and Oncology, vol. 15, no. 3, pp. 315328, 1989.

[25] F. E. Mohs, "Chemosurgery: a microscopically controlled method of cancer excision," Archives of Surgery, vol. 42, pp. 279-295, 1941.

[26] D. E. Rowe, R. J. Carroll, and C. L. Day Jr., "Mohs surgery is the treatment of choice for recurrent (previously treated) basal cell carcinoma," Journal of Dermatologic Surgery and Oncology, vol. 15, no. 4, pp. 424-431, 1989.

[27] M.-F. Avril, A. Auperin, A. Margulis et al., "Basal cell carcinoma of the face: surgery or radiotherapy? Results of a randomized study," British Journal of Cancer, vol. 76, no. 1, pp. 100-106, 1997.

[28] J. Y. Petit, M. F. Avril, A. Margulis et al., "Evaluation of cosmetic results of a randomized trial comparing surgery and radiotherapy in the treatment of basal cell carcinoma of the face," Plastic and Reconstructive Surgery, vol. 105, no. 7, pp. 2544-2551, 2000.

[29] A. W. Kopf, R. S. Bart, and D. Schrager, "Curettage electrodesiccation treatment of basal cell carcinomas," Archives of Dermatology, vol. 113, no. 4, pp. 439-443, 1977.

[30] M. K. Silverman, A. W. Kopf, C. M. Grin, R. S. Bart, and M. J. Levenstein, "Recurrence rates of treated basal cell carcinomas: part 2: curettage-electrodesiccation," Journal of Dermatologic Surgery and Oncology, vol. 17, no. 9, pp. 720-726, 1991.

[31] V. L. Hall, B. J. Leppard, J. McGill, M. E. Kesseler, J. E. White, and P. Goodwin, "Treatment of basal-cell carcinoma: comparison of radiotherapy and cryotherapy," Clinical Radiology, vol. 37, no. 1, pp. 33-34, 1986.
[32] M. R. T. M. Thissen, F. H. M. Nieman, A. H. L. B. Ideler, P. J. M. Berretty, and H. A. M. Neumann, "Cosmetic results of cryosurgery versus surgical excision for primary uncomplicated basal cell carcinomas of the head and neck," Dermatologic Surgery, vol. 26, no. 8, pp. 759-764, 2000.

[33] C. A. Morton, K. E. McKenna, and L. E. Rhodes, "Guidelines for topical photodynamic therapy: update," British Journal of Dermatology, vol. 159, no. 6, pp. 1245-1266, 2008.

[34] L. E. Rhodes, M. de Rie, Y. Enström et al., "Photodynamic therapy using topical methyl aminolevulinate vs surgery for nodular basal cell carcinoma: results of a multicenter randomized prospective trial," Archives of Dermatology, vol. 140, no. 1, pp. 17-23, 2004.

[35] J. K. Geisse, P. Rich, A. Pandya et al., "Imiquimod 5\% cream for the treatment of superficial basal cell carcinoma: a doubleblind, randomized, vehicle-controlled study," Journal of the American Academy of Dermatology, vol. 47, no. 3, pp. 390-398, 2002.

[36] H.-J. Schulze, B. Cribier, L. Requena et al., "Imiquimod 5\% cream for the treatment of superficial basal cell carcinoma: results from a randomized vehicle-controlled phase III study in Europe," British Journal of Dermatology, vol. 152, no. 5, pp. 939-947, 2005.

[37] J. Geisse, I. Caro, J. Lindholm, L. Golitz, P. Stampone, and M. Owens, "Imiquimod 5\% cream for the treatment of superficial basal cell carcinoma: results from two phase III, randomized, vehicle-controlled studies," Journal of the American Academy of Dermatology, vol. 50, no. 5, pp. 722-733, 2004.

[38] H. Gollnick, C. G. Barona, R. G. J. Frank et al., "Recurrence rate of superficial basal cell carcinoma following treatment with imiquimod $5 \%$ cream: conclusion of a 5 -year long-term follow-up study in Europe," European Journal of Dermatology, vol. 18, no. 6, pp. 677-682, 2008. 


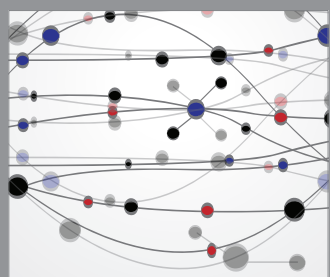

The Scientific World Journal
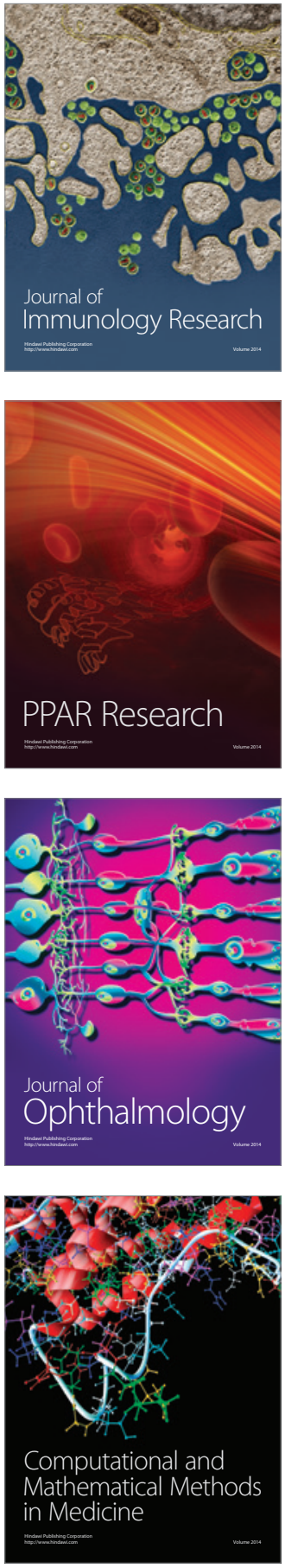

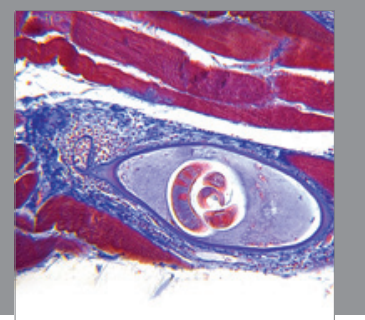

Gastroenterology

Research and Practice
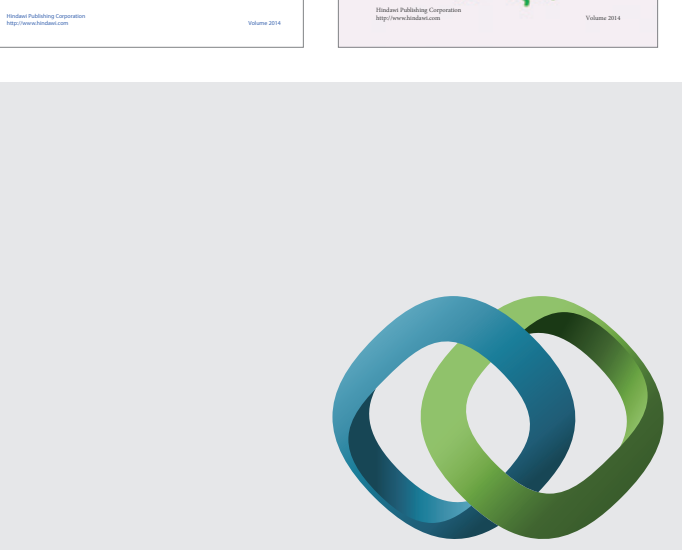

\section{Hindawi}

Submit your manuscripts at

http://www.hindawi.com
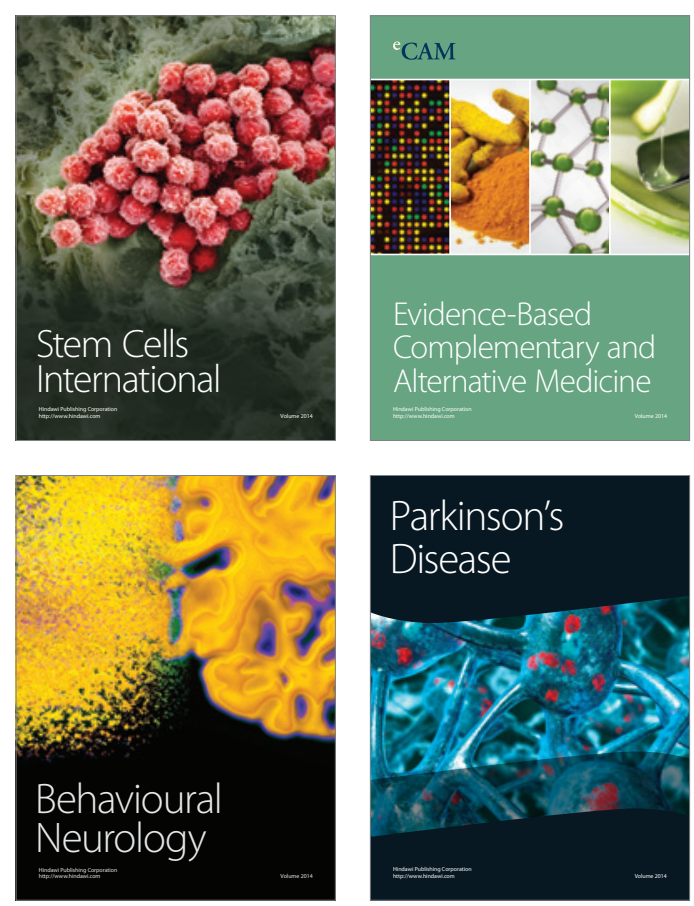

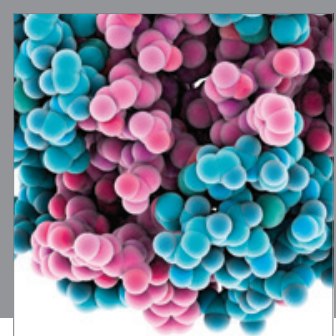

Journal of
Diabetes Research

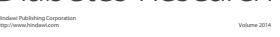

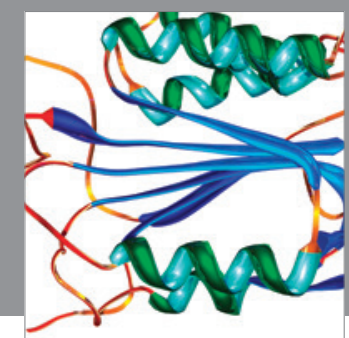

Disease Markers
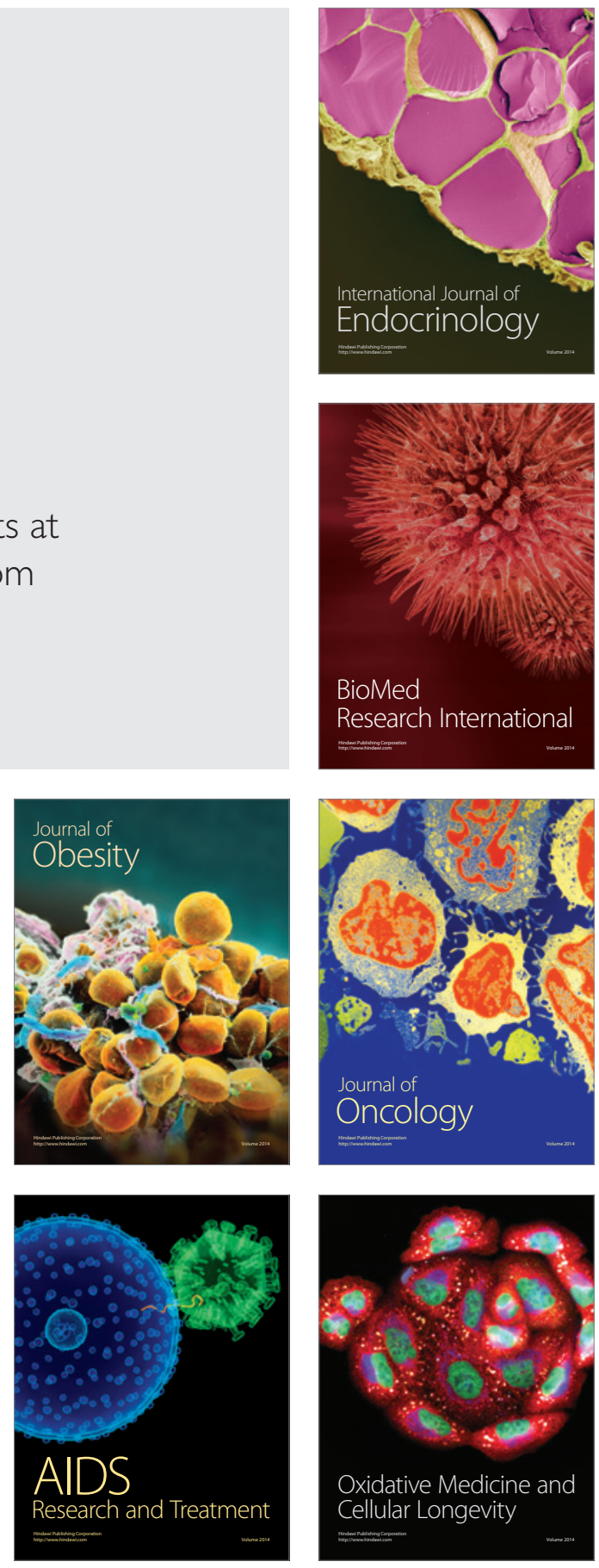